\title{
Simulation Investigation to Optimize a New Air-terminal System
}

\author{
Liu Dong \\ School of Aviation Science and Engineering \\ Beijing University of Aeronautics and Astronautics, \\ Beijing, China \\ 542497747@qq.com \\ Wang Minxing \\ School of Aviation Science and Engineering \\ Beijing University of Aeronautics and Astronautics, \\ Beijing, China \\ 214847191@qq.com
}

\author{
Pang Liping \\ School of Aviation Science and Engineering \\ Beijing University of Aeronautics and Astronautics, \\ Beijing, China \\ pangliping@buaa.edu.cn \\ Wang Jun \\ School of Aviation Science and Engineering \\ Beijing University of Aeronautics and Astronautics, \\ Beijing, China \\ wangjun@buaa.edu.cn
}

\begin{abstract}
Fresh air temperature supplied by an Environmental Control System (ECS) in a manned spacecraft is generally at $16^{\circ} \mathrm{C}$, which is a low air temperature if it is blow to the astronauts directly. In order to improve the thermal comfort, the supplied air temperature should be increased by reducing the amount of supplied air. However, the sleeping area in manned spacecraft should have a feature of warm and high flow velocity. Since the amount of $\mathrm{CO}_{2}$ will be easy to accumulate if the air velocity is not high enough. Yet high flow velocity and big amount of fresh air are easily to generate surface uncomfortable. This characteristic of sleeping area in manned spacecraft makes the requirement to optimize a new air-terminal system of sleeping area in manned spacecraft. This kind of new air-terminal system which should have some excellent properties, which can be easy to diffuse and ensure thermal comfort. This paper presents a kind of new air-terminal system of sleeping area in manned spacecraft which has a non-rotating working parts. The new air-terminal system ejects the cold fresh air which is enclosed by the warm return air that comes from the cabin. In this way, we can not only enhance the supply air temperature to ensure comfort, but also increase the amount of air flow to avoid the accumulation of $\mathrm{CO}_{2}$. To observe the performance of this new air-terminal system, this paper carries out the simulation investigation of the new air-terminal system of sleeping Area in manned spacecraft.
\end{abstract}

Keywords-Simulation Investigation; Air-terminal System; Manned Spacecraft; ECS

\section{INTRODUCTION}

The purpose of an Environmental Control System (ECS) in manned spacecraft cabin is to provide a comfortable and healthy living condition for astronauts by controlling the cabin temperature and dehumidifying the cabin relative humidity. A comfortable and healthy cabin environment can not only ensure the health of astronaut, but also effectively improve the quality of working efficiency. Due to the possibility of experiment research in spacecraft is small, and the computational fluid dynamics (CFD) numerical simulation technology has become an effective method. Numerical simulation technology has the superiorities of wide using, low cost and short research cycle.

In 1971, American McDonnell Douglas company developed a large-scale software G189A for manned spacecraft environmental control and life support systems. The software can simulate the pressure, temperature and humidity control system in spacecraft. But G189A software used a lumped parameter method without considering the spatial distribution of the parameters of the cabin ${ }^{[1]}$.In 1990, Hofacker used the PHOEN ICS software to simulate the temperature and convective heat flow field of the cabin ${ }^{[2]}$.Brad Eckhardt managed to mesh the complex geometry cabin of the international Space Station X-38 by importing TSS software SINDA to FLUENT software ${ }^{[3]}$

Over the years, many scholars have been proceeding the environmental control system simulation study of manned spacecraft .In 1993, Sar hent theoretical analyzed the problem of the minimum air speed to meet the requirements of thermal comfort and heat exchanger. When the speed of supply air reduced to $0.075 \mathrm{~m} / \mathrm{s}$, the cabin environment can still meet the cooling requirement of the astronauts. This conclusion had an important reference to the optimal design of the $\mathrm{ESC}^{[4]}$.In 1994, Chang studied the air distribution system of International Space Station and the air velocity range of different conditions in cabin by finite difference method and K-E equation turbulence model ${ }^{[5]}$.In 2000, Chaoyu Ji and Jianxun Ren studied the ventilation and heat exchanger in rectangular space ${ }^{[6]}$.However, few studies consider the air character of sleeping area in manned spacecraft.

The fresh air temperature supplied by the ECS in manned spacecraft is generally at $16{ }^{\circ} \mathrm{C}$, which is a low air temperature if it is blow to the astronauts directly. In order to improve the thermal comfort, the supplied air temperature should be increased by reducing the amount of supplied air. However, the sleeping area in manned spacecraft should have a feature of warm and high flow velocity. Since the amount of $\mathrm{CO} 2$ will be easy to accumulate if the air velocity is not high enough. Yet high flow velocity and big amount of fresh air prone to generate surface 
apathetic. This character of sleeping area in manned spacecraft raises the requirements to optimize a new air-terminal system of sleeping area in manned spacecraft. This kind of new air-terminal system which has excellent properties of easy-to-air diffusion and thermal comfort is urgently needed to study.

This paper presents a kind of new air-terminal system of sleeping area in manned spacecraft, which has a non-rotating working parts. The new air-terminal system ejects the cold fresh air which is enclosed by the warm return air that comes from the cabin. In this way, we can not only enhance the supply air temperature to ensure comfort, but also increase the amount of air flow to avoid the accumulation of $\mathrm{CO}_{2}$. To observe the performance of this new air-terminal system, this paper carries out the simulation investigation of the new air-terminal system of sleeping Area in manned spacecraft. In order to optimize the structure of the new air-terminal system, this paper evaluates the performance of the new air-terminal system by using the method of orthogonal experiment.

\section{STRUCTURE OF NEW AIR-TERMINAL SYSTEM}

The new air-terminal system for sleeping area in manned spacecraft will be studied in this, and its purpose to increase the terminal air supply on the human body comfort by increasing the temperature of supply air. In other hand, it can help to diffuse the carbon dioxide produced by the astronauts quickly by an amount of supply air with high velocity.

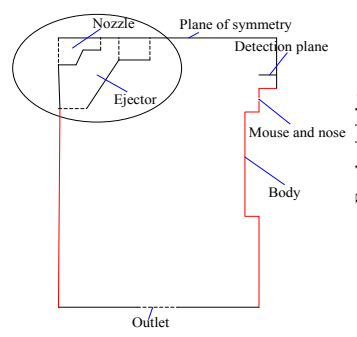

(a)

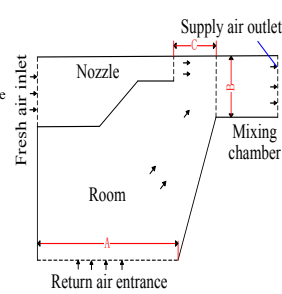

(b)
Figure 1. Structure of new air-terminal system of sleeping area in manned spacecraft

The new air-terminal system for sleeping area in manned spacecraft is shown in Fig .1.It is a non-rotating parts, and includes an nozzle, ejector room, fresh air inlet, supply air outlet and mixing chamber. Its work principle is like an ejector ${ }^{[7 \sim 8]}$. The cold fresh air with high press from inlet is increased by the nozzle, and then its pressure is decreased. The warm return air is inhaled by the lower pressure and mixes with the cold fresh air together in the mixing chamber, and then they flow from the supply air outlet.

In order to observe the effects of ejector structure parameters on suction amount of return air, inject ratio of fresh air and return air and supply air temperature, we will use the orthogonal test method to analyze. Different design structures will be compared by using this method.

The performance of the new air-terminal system will be evaluated in this paper by using the method of orthogonal experiment in order to optimize the structure of the new air-terminal system. Three aspects will be concentrated as following:
- Inject ratio of fresh air and secondary return air.

- Supply air velocity around head of astronaut.

- Distribution of $\mathrm{CO}_{2}$ around head of astronaut.

According the result of orthogonal experiment, we will analyzes the impacts of some elements of the new air-terminal system on the supply air condition, and then present a kind of optimal structure.

\section{OPTIMIZATION AND SIMULATION OF THE} NEW AIR-TERMINAL SYSTEM OF SLEEPING AREA

\section{A. Principle of orthogonal experiment}

An experiment need to have enough amount of data. This amount of experiment data will be very large If there are many experiment factors. It also brings the huge workload. Therefore, under the condition of many experiment factors, experiment design and data collection often proceed through scientific and artful method. Orthogonal experiment is an efficient experiment method for the muti-factor experiment by using orthogonal table. It only tests the representative factor combinations selected from entire combinations. Through the analysis to the selected factor combinations, the experiment will obtain a kind of optimal element combination.

The foremost feature of orthogonal experiment is using the selected factor combinations instead of the whole data. The selected factor combinations of orthogonal experiment can be distributed evenly in the whole data. This feature of orthogonal experiment greatly reduces workload, and gets appreciated in practice.

\section{B. Orthogonal experiment design}

The 2-d flow field model for the new air-terminal system of sleeping area in manned spacecraft is established in GAMBIT as shown in Fig .1(a) .The height of cabin model is $2 \mathrm{~m}$, and the width is $1.5 \mathrm{~m}$. The height of astronaut model is $1.6 \mathrm{~m}$, and the heat dissipation is 100W.The exhaled gas of astronaut model with the temperature at $34^{\circ} \mathrm{C}$ consists of carbon dioxide and air ${ }^{[9]}$. The mass flow-rate of carbon dioxide is $1.098 \times 10^{-5} \mathrm{~kg} / \mathrm{s}$, and the mass flow-rate of air is $1.25 \times 10^{-5} \mathrm{~kg} / \mathrm{s}$. A plane heat source is created to simulate the heat generated by the actual devices in the cabin. The heat dissipation of plane heat source is $800 \mathrm{~W}$. Symmetry plane is created in the model, and the model is shown only the half of the structure. The velocity of air that coms into nozzle is $2 \mathrm{~m} / \mathrm{s}$, and mass flow-rate of air is $0.24 \mathrm{~kg} / \mathrm{s}^{[10]}$. A plane is created above the head of astronaut model to measure the velocity of supply air.

In this paper, there are three variable structure elements of the new air-terminal system, and each element has three levels. The position of each element is shown in Fig .1(b). The width of secondary flow inlet $=40 \mathrm{~mm}, 80 \mathrm{~mm}, 120 \mathrm{~mm}$. The radius of mixing tube $=40 \mathrm{~mm}, 60 \mathrm{~mm}, 80 \mathrm{~mm}$. The distance between nozzle and mixing tube $=0 \mathrm{~mm}, 40 \mathrm{~mm}, 90 \mathrm{~mm}$.

\section{1) Design of orthogonal table}

The orthogonal table of $\mathrm{L}_{9}\left(3^{4}\right)$ is used in this paper. As there are only three variable elements in the experiment of this paper, the fourth element row of the orthogonal table is blank. Inject ratio is set as the performance evaluation criteria of orthogonal experiment. Inject ratio is defined as (1). 
TABLE I. ORTHOGONAL TABLE OF L $\mathrm{L}_{9}\left(3^{4}\right)$

\begin{tabular}{|c|c|c|c|c|}
\hline \multirow{2}{*}{ No. } & \multicolumn{3}{|c|}{ variable elements } & $\begin{array}{c}\text { Inject ratio } \\
(\%)\end{array}$ \\
\cline { 2 - 4 } & $\mathbf{A}(\mathbf{m m})$ & $\mathbf{B}(\mathbf{m m})$ & $\mathbf{C}(\mathbf{m m})$ & 30.0 \\
\hline 1 & 40 & 40 & 0 & 43.3 \\
\hline 2 & 40 & 60 & 40 & 46.7 \\
\hline 3 & 40 & 80 & 90 & 40.8 \\
\hline 4 & 80 & 40 & 40 & 34.2 \\
\hline 5 & 80 & 60 & 90 & 33.3 \\
\hline 6 & 80 & 80 & 0 & 42.5 \\
\hline 7 & 120 & 40 & 90 & 36.7 \\
\hline 8 & 120 & 60 & 0 & 48.3 \\
\hline 9 & 120 & 80 & 40 & \\
\hline
\end{tabular}

$$
u=\frac{M_{H}}{M_{P}} 100 \%
$$

where $\mathrm{u}$ is the inject ratio; $\mathrm{MH}$ is the mass flow-rate of new air; MP is the mass flow-rate of secondary air.

2) Range analysis of the result of orthogonal experiment

The purposes of range analysis are as following:

- Analyze the extent of the elements impact on the performance evaluation criteria.

- Place the three elements in order of priority according to their influence on the value of performance evaluation criteria.

- Propose the optimal level of each element and the optimal combination.

- The processes of range analysis are as follows:

- Calculate the sum value $\mathrm{K}$ of all levels of each element. The $\mathrm{K}$ is defined as (2).

- Calculate the average value $-\mathrm{k}$ of all levels of each element. The $-\mathrm{k}$ is defined as (3).

- Calculate the range value $\mathrm{R}$ of each element. The $\mathrm{R}$ is defined as (4).

- Propose the optimal level of each element according to the value of $-k$. Place the three elements in order of priority according to the value of $R$.

$$
\begin{gathered}
K_{j m}=\sum_{i=1}^{3} k_{j m i} \\
\overline{k_{j m}}=\frac{K_{j m}}{3} \\
R_{j}=\max \left(\overline{k_{j m}}\right)-\min \left(\overline{k_{j m}}\right)
\end{gathered}
$$

where $K_{j m}$ is the sum value of level $m$ of element $j ; k_{j m i}$ is the performance evaluation criteria value $\mathrm{i}$ of level $\mathrm{m}$ of element $\mathrm{j} ; \overline{\mathrm{k}}_{j m}$ is the average value of level $\mathrm{m}$ of element $\mathrm{j}$; $R_{j}$ is the range value of element $j$.

Because this paper ignores the interaction between each elements, the optimal combination is the assembly of each optimal level. The value of $R_{j}$ can reflect the extent of performance impact of element $j$ to the performance evaluation criteria. A higher value of $R_{j}$ indicates that the element $\mathrm{j}$ has a greater extent of performance impact to the performance evaluation criteria.

\section{Result of orthogonal experiment \\ 1) Value of inject ratio}

The inject ratio can reflect an entrainment ability by the new terminal air supply system in the manned spacecraft. The bigger it, the more the amount of entrainment return air, and the higher the supply air temperature. Therefore, a higher value of the inject ratio is good to increase the heat comfort. The range method of orthogonal experiment, $\mathrm{R}$ method, is used to analyze the inject ratio. The data is shown in the table 2.

The orthogonal test results show that the distance between the mixing pipe and the nozzle has a high effect on inject ratio. When the level of mixing pipe is at second level, the amount of injection air is highest. The optimal combination for the parameters of the new terminal air supply system structure is $\mathrm{A} 3 \mathrm{~B} 3 \mathrm{C} 2$.

TABLE II. EXTREME VALUE ANALYSIS OF INJECT RATIO

\begin{tabular}{|c|c|c|c|}
\hline & A & B & C \\
\hline $\mathrm{K}_{1}$ & 120.0 & 113.3 & 100 \\
\hline $\mathrm{K}_{2}$ & 108.3 & 114.2 & 132.4 \\
\hline $\mathrm{K}_{3}$ & 127.5 & 128.3 & 123.4 \\
\hline$\overline{\mathrm{k}}_{1}$ & 40.0 & 37.8 & 33.3 \\
\hline$\overline{\mathrm{k}}_{2}$ & 36.1 & 38.1 & 44.1 \\
\hline$\overline{\mathrm{k}}_{3}$ & 42.5 & 42.8 & 41.1 \\
\hline $\mathrm{R}$ & 6.4 & 5.0 & 7.8 \\
\hline Order & \multicolumn{3}{|c|}{$\mathrm{C}>\mathrm{A}>\mathrm{B}$} \\
\hline Optimum level & $\mathrm{A} 3 \mathrm{~B} 3 \mathrm{C} 2$ \\
\hline $\begin{array}{c}\text { Optimum } \\
\text { combination }\end{array}$ & \multicolumn{3}{|c}{} \\
\hline
\end{tabular}

2) Simulation of velocity over the head and $\mathrm{CO}_{2}$ concentration distribution

The velocity over the astronaut will affect the thermal comfort in the sleeping cabin. But a higher velocity is also needed because of quickly $\mathrm{CO}_{2}$ remove. Therefore, warm and high velocity supply air is good for the astronaut. In the following section, we will check the velocity of supply air and the $\mathrm{CO}_{2}$ concentration distribution in the sleeping cabin by using the FLUENT.

3) Velocity over the head

Velocity values will be obtained from the detection plane. Their average values are shown in Table 3.

TABLE III. AVERAGE VELOCITY OVER HEAD

\begin{tabular}{|c|c|c|c|}
\hline No. & $\begin{array}{c}\text { Average } \\
\text { velocity(m/s) }\end{array}$ & No. & $\begin{array}{c}\text { Average } \\
\text { velocity(m/s) }\end{array}$ \\
\hline 1 & 0.63 & 6 & 0.62 \\
\hline 2 & 0.64 & 7 & 0.89 \\
\hline 3 & 0.52 & 8 & 0.64 \\
\hline 4 & 0.76 & 9 & 0.69 \\
\hline 5 & 0.79 & & \\
\hline
\end{tabular}

From Table 1, we can observe that the average velocity is less than $1 \mathrm{~m} / \mathrm{s}$. It is good value for the astronaut because they will not have a strong cooling feeling.

4) $\mathrm{CO}_{2}$ concentration distribution

The volume fraction distributions of $\mathrm{CO}_{2}$ concentration are also shown in Fig .2. From Fig .2, we can observe that the volume fraction range of $\mathrm{CO}_{2}$ is between 0 and 0.001 , which meets the requirement of air quality. 


\section{Numerical analysis}

Assuming that the four experimental factors are independent from each other, we obtained the optimal configuration of which the sizes are calculated based on the orthogonal experiment table. Simulation results for the optimal configuration were compared with the orthogonal experiment table of nine different configurations to test the optimal configuration.

The optimal configuration of new air-terminal system:

- The width of secondary flow entrance is $120 \mathrm{~mm}$.

- The diameter of hybrid pipe is $80 \mathrm{~mm}$.

- The distance from the hybrid pipe to the nozzle is $40 \mathrm{~mm}$.

The simulation based on FLUENT for the optimal configuration led to the temperature profile and the volume fraction profile of carbon dioxide under the same conditions. In the profiles, the temperature range as shown in Fig .3(a) was set between $289 \mathrm{~K}$ with $310 \mathrm{~K}$ to display, while the volume fraction range of carbon dioxide as shown in Fig .3(b) was set between 0 with 0.001 to display for clear views.

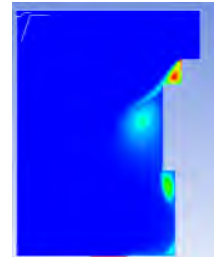

(a)

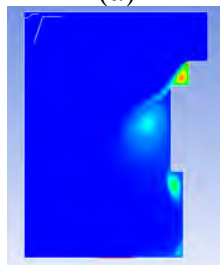

(d)

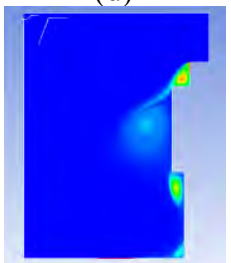

(g)

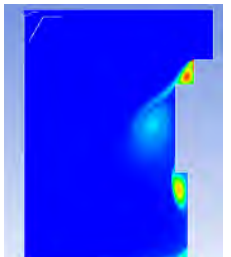

(b)

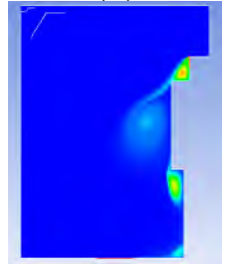

(e)

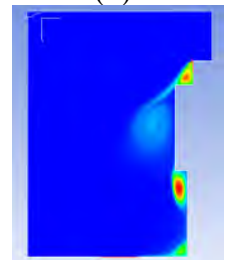

(h)

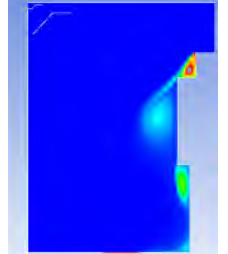

(c)

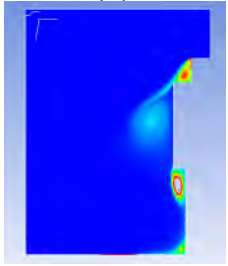

(f)

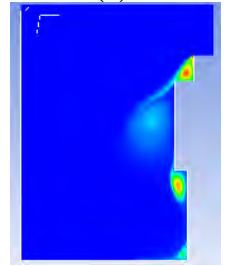

(i)
Figure 2. Volume fraction distributions of $\mathrm{CO} 2$ concentration

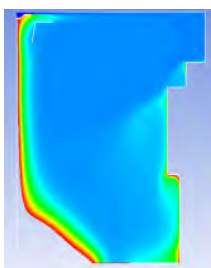

(a)

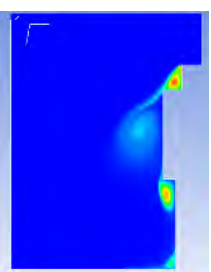

(b)
Figure 3. Profiles on the optimal configuration

According to the simulation results for the optimal configuration, the temperature is $19^{\circ} \mathrm{C}$ in the sleeping area of manned spacecraft, $3^{\circ} \mathrm{C}$ higher than that of new air, which makes humans more comfortable. The calculated average speed of upstream in the human head is $0.69 \mathrm{~m} / \mathrm{s}$, at which the distribution of volume fraction is appropriate and astronauts hardly feel cold. The ejecting ratio of the new air-terminal system at a high level of $48.3 \%$ brings in a large amount of warm air and keeps astronauts thermally comfortable.

\section{CONCLUSION}

The orthogonal test method is used to optimal the structure of a new terminal air supply system. By analyzing the orthogonal table, some benefit results are obtained to show the relationships of some design parameters, including the inlet width of return air, the diameter of mixing pipe and the distance of mixing pipe and nozzle. Further, the influence and the primary and secondary order of the some design parameters are determined. Finally, the optimal structure is obtained. The simulation results show the temperature of sleeping cabin is over $19^{\circ} \mathrm{C}$, the velocity over head is not very high, and the volume fraction concentration distribution of $\mathrm{CO}_{2}$ around the head is low. Therefore, the air quality and thermal comfort are satisfied together.

\section{ACKNOWLEDGMENT}

The research is sponsored by the Aviation Science Foundation of China (20130251005).

\section{REFERENCES}

[1] Berker R S, Blakely R S,“G189A-generalized environment/thermal control and life support systems computer program", Program Manual McDonnell Douglas Corp, Report M DAC G2444, 1971.

[2] Hofacker W, Huckle M. "Analyses of flow field in the H ERMES cabin",SAE901286.

[3] Eckhardt B, "International space stations X-38 crew return vehicle cabin condensation study", American Institute of Aeronautics and Astronautics, The Fifteenth AIAA Computational Dynamic Conference, California, 2001: 106111.

[4] Sar hent DH,"Minimum ventilation velocities for maintaining space station crew comfort", SAE932191.

[5] Chang S, Barker SR,US lab "a module cabin air distribution in space station",SAE932192.

[6] Ji Zhaoyue,Ren Jianxun,Liang Xingang, "Numerical Correlation of Convections in an Enclosure under Micro-gravity and terrestrial Gravity",Space Medicine\&Medical Engineering, 2000, 13(4) :281-285.

[7] Sokolov, “ejector”,Science Press, 1977.

[8] Lu Hongqi, “ Theory and Application of jet pump technology” ,China Water Power Press, 1989.

[9] Li Baizhan, “ Indoor thermal environment human thermal comfort” ,Chongqing University Press,2012.

[10] P.O.Wieland,"Living Together in Space:The Design and Operation of the Life Support Systems on the International Space Station",NASA/TM-1998- 206956/VOL1. 